\title{
COMPARATIVE STUDY OF REGULAR ALMOND CONSUMPTION'S EFFECT ON LIPID PROFILE IN NORMAL, OVERWEIGHT AND OBESE ADULTS.
}

1. MBBS, M.Phil

Assistant Professor

Department of Biochemistry

Central Park Medical College,

Lahore, Pakistan.

2. MBBS Student

Department of Biochemistry

Central Park Medical College,

Lahore, Pakistan.

3. MBBS Student

Department of Biochemistry Central Park Medical College,

Lahore, Pakistan.

4. MBBS, M.Phil, DIC, Ph.D Professor

Department of Biochemistry Central Park Medical College,

Lahore, Pakistan.

Correspondence Address:

Mirza Zeeshan Sikandar

Central Park Medical College,

31-km Ferozepur Road (Near Kahna

$\mathrm{Nau}$,

Lahore, Pakistan.

m.zee.shan@hotmail.com

Article received on:

09/02/2019

Accepted for publication:

24/07/2019
Farah Naz Tahir ${ }^{1}$, Haleema Nawaz², Mirza Zeeshan Sikandar ${ }^{3}$, Syed Imran Ali Shah ${ }^{4}$

ABSTRACT... Objectives: Obesity is a globally pervasive health concern linked to a plethora of cardiometabolic complications such as hypertension, dyslipidemia and hyperglycemia. Poor dietary proclivity contributes to dyslipidemia, however daily intake of nuts has previously been shown to improve abnormal blood lipid levels. The present study evaluated the effect of almond intake on the lipid profiles of normal, overweight and obese adults to discern which group benefits the most. Study Design: A prospective non-randomized comparative study design was employed. Setting: Institute of Molecular Biology and Biochemistry, University of Lahore and Department of Biochemistry, Central Park Medical College, Lahore. Period: May 2018 and December 2018. Material \& Methods: A total of 34 adult subjects (males and females) were recruited for the study with an age range from 21 to 60 years. Participants were categorized into normal, overweight and obese groups based on their Body Mass Index (BMI) values. Baseline fasting blood samples were drawn from each subject and stored. The subjects were then asked to consume $50 \mathrm{~g} /$ day almonds (without peel) for 30 days after which blood samples were again collected from each subject. Both baseline and post-supplementation serum samples were subjected to lipid profile analysis. Result: Almond supplementation resulted in lowered cholesterol, LDL and VLDL levels (p-values of $0.0001,0.001$ and 0.003 , respectively) in Group 1 (normal weight). Lowered cholesterol levels were also observed ( $p$-value 0.007 ) in Group 2 (overweight). There was no significant change in lipid profile in Group 3 (overweight), upon supplementation. Conclusion: Regular almond supplementation offers improvement in lipid profile and such beneficial effects of almond consumption on lipid profile are more pronounced in normal weight individuals than overweight or obese ones.

Key words: Dyslipidemia, Lipid Profile, Obesity, Supplementation.

Article Citation: Tahir FN, Nawaz H, Siknadar MZ, Shah SIA. A comparative study of regular almond consumption's effect on lipid profile in normal, Overweight and Obese adults. Professional Med J 2019; 26(12):2116-2121.

DOI: 10.29309/TPMJ/2019.26.12.3272

\section{INTRODUCTION}

Obesity is a serious medical condition marked by the accumulation of body fat to an unhealthy degree. ${ }^{1}$ Multiple factors contribute to the onset of obesity including genetics, sedentary lifestyle, endocrine disorders, anti-psychotic drug therapy etc. $^{2,3}$ Obese individuals are at a greater risk of developing serious and potentially life-threatening disorders such as type 2 diabetes mellitus, cardiovascular diseases, osteoarthritis, cancer etc. ${ }^{4}$ These co-morbidities are further associated with higher mortality rates in obese individuals.

Obese and overweight individuals are generally more prone to metabolic disruptions such as hyperglycemia, insulin resistance and dyslipidemias. ${ }^{7-9}$ Dyslipidemias are common in developed countries where obesity is more prevalent. $^{10}$ Dyslipidemias are a primary risk factor for cardiovascular and metabolic disorders. ${ }^{11}$ Lifestyle modifications and/or medical intervention are necessary for obese and dyslipidemic individuals. In the United States, more than one-quarter of adults are dyslipidemic or are prescribed lipid-lowering medication. ${ }^{12}$

In addition to pharmaceutical therapy, lipid levels can be controlled by modifying dietary factors; best results are exhibited by reducing saturated and trans-fat intake and increasing polyunsaturated and monounsaturated fat intake. ${ }^{13}$ Tree nuts such as almonds are low 
in saturated fats and rich in unsaturated fats, a-tocopherols and phytochemicals. Current studies have demonstrated improvement in blood LDL and serum cholesterol levels with the addition of almonds to diet. ${ }^{14-16}$ Some studies have also demonstrated weight loss with almond intake, possibly due to its satiating properties and boosting of metabolism. ${ }^{17-19}$ Therefore, almond intake could possibly reduce the risk of lethal disease in obese and overweight individuals and prove beneficial in preventing / mitigating dyslipidemia and obesity.

To our knowledge, no adequately designed study has been conducted locally to observe the effect of almond intake on lipid profile in obese, overweight and normal weight individuals. The present study was aimed at determining the potential positive impact of almond consumption on lipid profile in the local population and to observe which weight group benefited the most.

\section{MATERIALS AND METHODS}

A prospective non-randomized comparative study design was employed for this research study. The study was carried out at Institute of Molecular Biology and Biochemistry, University of Lahore and Department of Biochemistry, Central Park Medical College, Lahore. The study was conducted between May 2018 and December 2018. The study was approved by the Central Park Research Committee.

A total of 34 subjects were recruited for the study. Written informed consent was procured from each participant prior to enrollment. Individuals with hypertension, diabetes mellitus, hypersensitivity to almonds, peptic ulcer, kidney disease, cardiovascular disorders, malignancy, urinary tract infections or taking lipid-lowering medications were excluded from the study. Pregnant females were also excluded. Participants' body mass index (BMI) values were calculated after measuring their height (in meters) and weight (in kilograms) by using the formula: weight in kilograms divided by height in meters squared. Based on their BMI values, participants were divided into three groups; Group $1(n=16)$ normal weight (BMI 18.5-24.9), Group $2(n=11)$ overweight (BMI 25-29.9) and Group $3(n=7)$ obese $(\mathrm{BMI}>30)$.

After recruitment and group allocation, subjects were provided instructions about the dose of almonds (50 grams per day) and timing of intake. Subjects were asked to stop the consumption of potential lipid lowering ingredients like garlic, ginger etc. for a period of one month. American variety of almonds weighing 50 grams were packed into plastic bags and 30 packets were given to each subject. Subjects were advised to take one packet daily (for a dose of 50 grams/day) before breakfast. The subjects were advised to continue with their usual diet and physical activity for the study period of one month.

Blood samples were collected from each subject at two separate instances; once at baseline i.e. prior to almond consumption and once on the $31^{\text {st }}$ day i.e. subsequent to almond intake. Fasting blood samples were collected for which the subjects were advised not to eat or drink anything except water for a period of 12 hours before sample collection. Early morning samples were collected after an overnight fast. $5 \mathrm{ml}$ blood was drawn into a vacutainer tube without anticoagulant using standard sterile venipuncture technique. The collected blood samples were incubated at room temperature for half an hour in upright position and then they were centrifuged for 15 minutes at 2000 revolutions per minute. The supernatant containing serum was collected in clean Eppendorf tubes and stored at $4^{\circ} \mathrm{C}$. Lipid profile assays were performed for serum cholesterol, LDL, HDL, VLDL and triglycerides using commercially available kits.

The data were entered into an excel sheet (Microsoft Office) and then imported into SPSS version 23 for analysis. Mean + SD were calculated for quantitative variables. One-way ANOVA was performed to assess group mean differences followed by employment of paired sample $t$ test within groups for determination of differences with in groups where p-values $<0.05$ were regarded as significant. 


\section{RESULTS}

The age of subjects (Mean + S.D.) was $36.08+$ 11.45 years. Upon applying ANOVA, no significant difference was observed in the values of any of the studied lipid profile parameters between the three groups, either at baseline or after supplementation (Table-I). This finding reflected that the lipid profile status in each group were well-matched. The following results were obtained on applying paired sample t-test on individual lipid profile parameters in each of the three groups (TablesII-IV). Group 1 showed significant reduction in post-supplementation fasting serum cholesterol levels (Mean + SD mg/dl; Baseline 213.41 + 45.7 vs. Post-supplementation $179.11+38.18$; $\mathrm{p}=0.0001$ ) (Table-II). Similarly, significantly lowered serum fasting LDL levels were observed
(Mean + SD mg/dl; Baseline 128.97 + 38.01 vs. Post-supplementation $110.82+29.56 ; p=0.001$ ) (Table-II) Amelioration in serum fasting VLDL was also observed (Mean + SD mg/dl; Baseline 33.02 +15.65 vs. Post-supplementation $27.94+12.7$; $p=0.003$ ). Some beneficial effects of almond supplementation were also reflected through the results observed in Group 2. Cholesterol levels were reduced after almond intake with a significant difference in serum levels before (Mean + SD mg/dl; $222.36+57.69)$ and after almond supplementation (Mean + SD mg.dl; $192.72+42.68)(p=0.007$ (Table-III). There was no improvement in any other parameter. Group 3 displayed no significant difference in any of the studied parameters of lipid profile pre- and postalmond supplementation (Table-IV).

\begin{tabular}{|l|c|c|c|c|}
\hline \multicolumn{1}{|c|}{ Parameter } & $\begin{array}{c}\text { Group 1 }(\mathbf{n = 1 6 )} \\
\text { Mean + S.E.M. }\end{array}$ & $\begin{array}{c}\text { Group 2 }(\mathbf{n = 1 1 )} \\
\text { Mean + S.E.M. }\end{array}$ & $\begin{array}{c}\text { Group 3 }(\mathbf{n = 7}) \\
\text { Mean + S.E.M. }\end{array}$ & P-Value \\
\hline Cholesterol before supplementation $(\mathrm{mg} / \mathrm{dl})$ & $200.81+9.99$ & $222.36+17.39$ & $228.14+12.71$ & 0.316 \\
\hline Cholesterol after supplementation $(\mathrm{mg} / \mathrm{dl})$ & $171.18+7.24$ & $192.72+12.86$ & $175.85+18.38$ & 0.354 \\
\hline HDL before supplementation $(\mathrm{mg} / \mathrm{dl})$ & $38.81+1.48$ & $43.54+1.94$ & $39.42+.89$ & 0.101 \\
\hline HDL after supplementation $(\mathrm{mg} / \mathrm{dl})$ & $42.37+3.12$ & $39.36+2.32$ & $44.71+2.93$ & 0.550 \\
\hline LDL before supplementation $(\mathrm{mg} / \mathrm{dl})$ & $124.0+8.88$ & $134.00+12.41$ & $132.42+16.20$ & 0.780 \\
\hline LDL after supplementation $(\mathrm{mg} / \mathrm{dl})$ & $103.81+7.87$ & $120.72+7.74$ & $111.28+11.43$ & 0.355 \\
\hline TAG before supplementation $(\mathrm{mg} / \mathrm{dl})$ & $153.81+17.96$ & $120.72+7.74$ & $117.71+29.40$ & 0.735 \\
\hline TAG after supplementation $(\mathrm{mg} / \mathrm{dl})$ & $151.25+14.31$ & $173.18+26.55$ & $183.57+38.41$ & .606 \\
\hline VLDL before supplementation $(\mathrm{mg} / \mathrm{dl})$ & $31.43+3.06$ & $34.36+5.33$ & $34.57+7.91$ & .863 \\
\hline VLDL after supplementation $(\mathrm{mg} / \mathrm{dl})$ & $26.62+3.05$ & $29.18+3.39$ & $29.00+6.53$ & .859 \\
\hline
\end{tabular}

Table-I. Multiple group comparisons of lipid profile parameters

\begin{tabular}{|l|c|c|c|}
\hline \multicolumn{1}{|c|}{ Parameter } & $\begin{array}{c}\text { Before } \\
\text { (Mean + S.D.) }\end{array}$ & $\begin{array}{c}\text { After } \\
\text { (Mean + S.D.) }\end{array}$ & P-Value \\
\hline Cholesterol $(\mathrm{mg} / \mathrm{dl})$ & $213.41+45.7$ & $179.11+38.18$ & $.0001^{*}$ \\
\hline $\mathrm{HDL}(\mathrm{mg} / \mathrm{dl})$ & $40.47+5.85$ & $41.82+10.19$ & .481 \\
\hline LDL $(\mathrm{mg} / \mathrm{dl})$ & $128.97+38.01$ & $110.82+29.56$ & $.001^{*}$ \\
\hline TAG $(\mathrm{mg} / \mathrm{dl})$ & $165.00+77.15$ & $164.00+73.66$ & .880 \\
\hline VLDL $(\mathrm{mg} / \mathrm{dl})$ & $33.02+15.65$ & $27.94+12.7$ & $.003^{*}$ \\
& \multicolumn{2}{|c|}{$\begin{array}{c}\text { Table-II. Effect of almond supplementation on lipid profile in normal weight subjects. } \\
\text { *Difference is significant at p-value < } \mathbf{0 . 0 5}\end{array}$} \\
\end{tabular}

\begin{tabular}{|c|c|c|c|}
\hline Parameter & $\begin{array}{c}\text { Before } \\
\text { (Mean + S.D.) }\end{array}$ & $\begin{array}{c}\text { After } \\
\text { (Mean + S.D.) }\end{array}$ & P-Value \\
\hline Cholesterol (mg/dl) & $222.36+57.69$ & $192.72+42.68$ & .007 \\
\hline $\mathrm{HDL}(\mathrm{mg} / \mathrm{dl})$ & $43.54+6.45$ & $39.36+7.69$ & .154 \\
\hline LDL (mg/dl) & $134.00+41.16$ & $120.72+25.70$ & .144 \\
\hline TAG (mg/dl) & $173.18+88.07$ & $170.09+78.85$ & .800 \\
\hline VLDL (mg/dl) & $34.36+17.68$ & $29.18+11.26$ & .143 \\
\hline
\end{tabular}




\begin{tabular}{|l|c|c|c|}
\hline \multicolumn{1}{|c|}{ Parameter } & $\begin{array}{c}\text { Before } \\
\text { Mean + S.D. }\end{array}$ & $\begin{array}{c}\text { After } \\
\text { Mean + S.D. }\end{array}$ & P-Value \\
\hline Cholesterol $(\mathrm{mg} / \mathrm{dl})$ & $228.14+33.64$ & $175.85+48.64$ & .012 \\
\hline HDL $(\mathrm{mg} / \mathrm{dl})$ & $39.42+2.37$ & $44.71+7.76$ & .083 \\
\hline LDL $(\mathrm{mg} / \mathrm{dl})$ & $132.42+42.86$ & $111.28+30.25$ & .336 \\
\hline TAG $(\mathrm{mg} / \mathrm{dl})$ & $177.71+79.11$ & $183.57+101.64$ & .697 \\
\hline VLDL $(\mathrm{mg} / \mathrm{dl})$ & $34.57+20.44$ & $29.0+17.30$ & .280 \\
\hline \multicolumn{2}{|r|}{ Table-IV. Effect of almond supplementation on lipid profile parameters in obese subjects. } \\
\end{tabular}

\section{DISCUSSION}

Obesity and its related metabolic complications are considered a grave health concern globally. Adverse lipid changes associated with weight gain are implicated in the development cardiovascular complications with a high mortality and morbidity. ${ }^{8}$ Nutritional manipulation of lipid profile is an emerging modality with therapeutic and preventive value. The present study looked at the effect of almond supplementation on serum lipid values in obese and overweight individuals and compared them with adults having normal weight.

On assessment of the various parameters of fasting lipid profile, prominent beneficial effects were revealed in normal weight subjects. Almond supplementation was associated with decrease in serum total cholesterol, LDL and VLDL levels, with the effect being highly contingent on individuals' $\mathrm{BMI}$ values as demonstrated by Abazarfard et al..$^{20}$ A decline in serum cholesterol levels was also observed in both overweight and lean subjects after the month-long almond intervention in addition to the decrease observed in serum LDL and VLDL in normal weight individuals. The observed improvement in lipid profile associated with almond supplementation in normal weight individuals may be more marked because of better metabolism seen in such individuals as documented by Kanwar et al. ${ }^{21}$ Previously, life style modifications such as regular exercise and almond supplementation have shown noticeable increase in BMI in children under the age of 14, as described by Kelishadi et al. ${ }^{22}$ Conversely, decrease in BMl and waist-to-hip ratios have been reported in adults after supplementation with almonds, which has been attributed to metabolic differences between adults and children. ${ }^{23}$ Thus, nutritional modifications such as almond supplementation are more likely to influence the biochemical and anthropometric measures in a positive way in metabolically healthy individuals with weight within the normal range.

The current negative results on serum TAG levels are consistent with a previous study by Liu et al. that exhibited no change in TAG levels subsequent to almond intake. ${ }^{19}$ The present study did not show any effect on HDL levels in any of the groups which is in accordance with Wein et al. who reported that almond supplementation has no effect over HDL values in overweight individuals. The probable reason for this may be the compromised efficacy of lipoprotein lipase owing to insulin insensitivity, which is now regarded as an attribute of obesity. ${ }^{24}$

The present study was limited by the small sample size and apparently uneven age/sex distribution between the groups. Larger future studies with appropriately matched groups are warranted to ensure that findings are robust enough for their generalization to local population.

\section{CONCLUSION}

Almond supplementation results in improvement of lipid profile, but the effect is more marked in normal weight individuals as compared to overweight and obese individuals. Caloric restriction, exercise and similar lifestyle modifications aimed at weight reduction may be advised to obese and overweight subjects to augment the beneficial impact of almond supplementation on serum lipid profile.

\section{ACKNOWLEDGEMENT}

We are thankful to Prof. Asim Mumtaz (Department of Pathology, Central Park Medical College) for his valuable input in the design and review of this 
study.

Copyright@ 24 July, 2019.

\section{REFERENCES}

1. Allison, D, B., Fontaine, K, R., Manson, J, E., Stevens, J. \& Vanltallie, T, B. Annual deaths attributable to obesity in the United States. JAMA. 1999; 282(16):1530-8.

2. World Health Organization. (2018). Obesity and overweight. [online] Available at: http://www.who.int/ news-room/fact-sheets/detail/obesity-and-overweight

3. Yazdi, F., Clee, S. and Meyre, D. Obesity genetics in mouse and human: back and forth, and back again. Peer J, 2015; 3:e856.

4. Haslam, D. and James, W. Obesity. Lancet. 2005; 366(9492):1197-1209.

5. WHO Expert Consultation. Appropriate body-mass index for Asian populations and its implications for policy and intervention strategies. Lancet, 2004; 363(9403):..157-63.

6. Bray, G. Medical consequences of obesity. J Clin Endocrinol Metab. 2004; 89(6):2583-9.

7. Lima, S., Arrais, R., Almeida, M., Souza, Z. and Pedrosa, L. Plasma lipid profile and lipid peroxidation in overweight or obese children and adolescents. $J$ de Pediatria, 2004:80(1):23-8.

8. Khan, M. and Khaleel, M. Comparative study of serum lipid profile of obese and non-obese students (male) of Aljouf University. Int $\mathrm{J}$ Biomedical Advance Res. $2016 ; 7(1): 35-7$.

9. Rinaldi, A., Oliveira, E., Moreto, F., Gabriel, G., Corrente, J. and Burini, R. Dietary intake and blood lipid profile in overweight and obese schoolchildren. BMC Res Notes. 2012; 5(1): 598-604.

10. Bhurosy, T. and Jeewon, R. Overweight and obesity epidemic in developing countries: A problem with diet, physical activity, or socioeconomic status? Scientific World J. 2014.1-7.

11. Nelson, R. Hyperlipidemia as a risk factor for cardiovascular disease. Prim Care. 2013; 40(1):195211.

12. Jeong, J., Kwon, $H$. Prevalence and clinical characteristics of dyslipidemia in koreans. Endocrinol Metab (Seoul). 2017; 32(1):30-35.

13. Kelly, R. Diet and exercise in the management of hyperlipidemia. Am Fam Physician. 2010; 81(9):10971102.
14. Musa-Veloso, K., Paulionis, L., Poon, T. and Lee, H. The effects of almond consumption on fasting blood lipid levels: A systematic review and meta-analysis of randomized controlled trials. J Nutr Sci. 2016; 5:e34.

15. Lee, Y., Berryman, C., West, S., Chen, C., Blumberg, J., Lapsley, K., Preston, A., Fleming, J. and Kris $\square$ Etherton, P. Effects of dark chocolate and almonds on cardiovascular risk factors in overweight and obese individuals: A randomized controlled $\square$ feeding trial. J Am Heart Assoc. 2017; 6(12):e005162.

16. Abazarfard, Z., Eslamian, G., Salehi, M. and Keshavarzi, $S$. A randomized controlled trial of the effects of an almond-enriched, hypocaloric diet on liver function tests in overweight/obese women. Iran Red Crescent Med J. 2016; 18(3):e23628.

17. Dhillon, J., Tan, S., Mattes, R. Almond consumption during energy restriction lowers truncal fat and blood pressure in compliant overweight or obese adults. J Nutr. 2016; 146(12):2513-9

18. Abazarfard, Z., Salehi, M., Keshavarzi, S. The effect of almonds on anthropometric measurements and lipid profile in overweight and obese females in a weight reduction program: A randomized controlled clinical trial. J Res Med Sci. 2014; 19(5):457-64.

19. Liu, Y., Hwang, H., Ryu, H., Lee, Y., Kim, H., Park, H. The effects of daily intake timing of almond on the body composition and blood lipid profile of healthy adults. Nutr Res Pract. 2017; 11(6):479-86.

20. Abazarfard, Z., Eslamian, G., Salehi, M. and Keshavarzi, $S$. A randomized controlled trial of the effects of an almond-enriched, hypocaloric diet on liver function tests in overweight/obese women. Iran Red Crescent Med J. 2016; 18(3):e23628.

21. Kanwar, G., Kabra, R. A study of association between obesity and lipid profile. IJRNASS 2016; 4(4):69-74.

22. Kelishadi, R., Hashemipour, M., Sheikh-Heidar, A, Ghatreh-Samani, S. Changes in serum lipid profile of obese or overweight children and adolescents following a lifestyle modification course. ARYA Atheroscler 2012; 8(3):143-8.

23. Abazarfard, Z., Eslamian, G., Salehi, M., Keshavarzi, $S$. The effect of almonds on anthropometric measurements and lipid profile in overweight and obese females in a weight reduction program: A randomized controlled clinical trial. J Res Med Sci. $2014 ; 19(5): 457-64$.

24. Wien, M, A., Sabate, M, J., Ikle, N, D., Cole, E, S., Kandeel, R, F. Almonds vs complex carbohydrates in a weight reduction program. Int $\mathrm{J}$ Obes. 2003; 27:1365-72. 


\begin{tabular}{|c|c|c|c|}
\hline \multicolumn{3}{|c}{ AUTHORSHIP AND CONTRIBUTION DECLARATION } \\
\hline Sr. \# & Author(s) Full Name & \multicolumn{1}{|c|}{ Contribution to the paper } & Author(s) Signature \\
\hline 1 & Farah Naz Tahir & $\begin{array}{l}\text { Conception, Literature search, Study } \\
\text { design, Data collection, Data analysis as } \\
\text { well as manuscript drafting. } \\
\text { Conception, Study design, data } \\
\text { collection, data analysis as well as } \\
\text { manuscript drafting. } \\
\text { Literature search, Study design, Data } \\
\text { collection, data analysis as well as } \\
\text { manuscript drafting. } \\
\text { Conception, data analysis and } \\
\text { interpretation of analysis as well as } \\
\text { manuscript drafting. }\end{array}$ \\
\hline 4 & Haleema Nawaz & Syed Imran Ali Shah \\
\hline
\end{tabular}

